\title{
PREDICTING THE MARKET POTENTIAL OF PLUG-IN ELECTRIC VEHICLES USING MULTIDAY GPS DATA
}

\author{
Mobashwir Khan \\ The University of Texas at Austin \\ 1.120. Cockrell Jr. Hall \\ Austin, TX 78712-1076 \\ mobashwir@gmail.com \\ Kara M. Kockelman \\ (Corresponding author) \\ Professor and William J. Murray Jr. Fellow \\ Department of Civil, Architectural and Environmental Engineering \\ The University of Texas at Austin \\ 6.9 E. Cockrell Jr. Hall \\ Austin, TX 78712-1076 \\ kkockelm@mail.utexas.edu \\ Phone: 512-471-0210
}

The following paper is a pre-print and the final publication can be found in Energy Policy 46: 225-233, 2012.

Presented at the Transportation Research Board’s $91^{\text {st }}$ Annual Meeting, January 2012

\begin{abstract}
GPS data for a year's worth of travel by 255 Seattle households illuminate how plug-in electric vehicles can match household needs. The results suggest that a battery-electric vehicle (BEV) with 100 miles of range should meet the needs of 50\% of one-vehicle households and $80 \%$ of multiple-vehicle households, when charging once a day and relying on another vehicle or mode just 4 days a year. Moreover, the average one-vehicle Seattle household uses each vehicle 23 miles per day and should be able to electrify close to $80 \%$ of its miles using a plug-in hybrid electric vehicle (PHEV) with 40-mile all-electric-range. Households owning two or more vehicles can electrify 50 to $70 \%$ of their miles using a PHEV40, depending on how they assign the vehicle across drivers each day. Cost comparisons between the average single-vehicle household owning a Chevrolet Cruze versus a Volt PHEV suggest that when gas prices are \$3.50 per gallon and electricity rates at $11.2 \mathrm{ct}$ per $\mathrm{kWh}$, the Volt will save the household \$535 per year in operating costs. Similarly, the Toyota Prius PHEV will provide an annual savings of \$538 per year over the Corolla.
\end{abstract}

Key words: Plug-in Electric Vehicles, Battery-electric Vehicles, Long-Term Vehicle Use

\section{BACKGROUND}

Energy-security concerns, the rising cost of petroleum, and climate change considerations make plug-in electric vehicles (PEVs) an intriguing alternative to conventional internal combustion engine (ICE) vehicles. PEVs run partially or fully on electric power from an externally charged battery. PEVs include battery-electric vehicles (BEVs) and plug-in hybrid electric vehicles 
(PHEVs). BEVs are driven by an electric motor while PHEVs include an ICE for conventional power as needed. PHEVs can function in different modes and different configurations. Readers are referred to Vyas and Santini (2009) for details of different PEV technologies and to Taylor (2009) for a detailed comparison of BEVs and PHEVs. PHEVs are usually denoted by PHEVx, where $x$ refers to the vehicle's all-electric range (AER). The AER is the distance the vehicle is able to travel purely on electricity under average driving conditions.

PEV technology tends to be more expensive than ICE technology because of the high cost of batteries. Until recently, a BEV with an AER of 100 miles was estimated to cost the manufacturer at least $\$ 16,000$ more than a comparable conventional vehicle (Sperling and Lutsey 2009, and Frost and Sullivan 2009a), and a PHEV20 and PHEV40 were estimated to cost $\$ 8,000$ and $\$ 11,000$ more, respectively (Simpson 2006). While such costs are generally falling, even differences of $\$ 5,000$ make electric vehicles less accessible to cost-sensitive customers. Although many governments now provide financial and non-financial incentives to early adopters, the observed cost differences remain high. In addition, there are uncertainties of battery-replacement costs, energy savings and resale value. Currently, the U.S. government provides an income tax rebate of up to $\$ 7,500$ per vehicle (depending on the battery size), and California buyers can receive another $\$ 5,000$ from the Clean Vehicle Rebates Project (Center for Sustainable Energy 2011).

The benefits of switching to PEVs are many, including greater energy-security, as nations can reduce reliance on foreign sources of oil (Fontaine 2008, Greene 2010a). PEVs should also reduce green-house gas (GHG) emissions in most settings (Kintner-Mayer et. al. 2007, Samaras and Meisterling 2008, and Sioshansi and Denholm 2009) and shift other emissions away from polluted urban centers by reducing (or eliminating) tailpipe emissions (Thomas 2009, Duvall and Knipping 2007). The 2010 Chevy Volt is rated by the U.S. Environmental Protection Agency (EPA) to travel 93 miles per gallon of equivalent electricity (with one gallon of gasoline rated equivalent to $33 \mathrm{~kW}$-hr of electricity). In fact, the higher purchase price of electric vehicles may be recovered over several years of operation. For example, Tuttle and Kockelman (2012) showed how the net cost of a Nissan Leaf BEV compared to a similarly sized conventional Nissan Versa drops to $\$ 250$ within ten years of operation at gasoline and electricity prices of $\$ 3.00$ per gallon and 11.75 ct per kWh, respectively. Simpson (2006) and Lemoine et al. (2008) concluded that higher gasoline prices and lower manufacturing costs of batteries are key to making PEVs economically feasible in the long run.

One of the biggest hurdles to BEV adoption is "range anxiety", where owners worry about being stranded roadside with a fully discharged battery (Tate et. al. 2008, TEP 2011). Higher AERs reduce range anxiety, but at the expense of higher manufacturing costs. AER is also important for PHEV owners since it determines the percentage of miles that are electrified, thereby impacting fuel cost savings. Manufacturers need to know what AERs are most suitable for different consumer markets.

This paper addresses such questions. For the manufacturers, it suggests what percentage of the U.S. market may be well-served under multiple AER scenarios (for BEVs and PHEVs). For consumers, it tackles questions like: What percentage of driving days can be accommodated using BEVs of certain AERs? What percentage of miles will be electrified under different PHEV 
design scenarios? And what savings can households expect in the long run? Honest answers to such questions may allow manufactures and consumers to overcome various concerns they have and pursue a PEV future.

Vyas and Santini (2009) sought to address similar questions by relying on the United States 1day National Household Travel Survey (NHTS) data from 2001. Gonder et al. (2007) used oneday GPS data from St. Louis driving to predict gasoline savings under PHEV20 and PHEV40 scenarios and concluded that GPS data significantly enhance results, since analysts can discern detailed driving profiles that affect fuel consumption. They estimated that PHEVs can reduce a vehicle's fuel consumption by roughly $50 \%$ compared to conventional vehicles. More recently, Pearre et al. (2011) analyzed multi-day GPS data over a full year from 484 instrumented vehicles in Atlanta, Georgia. Their results suggest that a substantial fraction of the sampled fleet (32\%) may be able to switch to 100-mile AER BEVs if they are willing to adjust driving patterns just 6 days a year.

Both Vyas and Santini (2009) and Gonder et al. (2007) focused on PHEVs and used one-day data sets. This research uses GPS data over a one-year period, but from the Seattle area and examines both PHEV and BEV adoption scenarios. It also estimates annual cost savings for single-vehicle households who are willing to switch to a PEV. In addition, the sample is weighted to reflect the Seattle population and single- and multiple-vehicle households are analyzed separately, since multiple-vehicle households have added flexibility when switching just one of their vehicles to a PEV. The goal is to describe PEV adoption rates in light of travel behavior patterns and household types.

The rest of the paper is organized as follows: first, key characteristics of present and forthcoming PEVs are described, so readers are familiar with purchase options. Then, the long-term Seattle driving data are discussed, along with a brief explanation of the merits of using multi-day data. These data are analyzed to determine reasonable adoption and use profiles and ownership cost implications along with utility factors.

\section{CURRENT AND UPCOMING PEVs}

The Tesla Roadster (a BEV) has sold more than 1500 units in 30 countries since its 2008 release (Gordon-Bloomfield 2011), and the Chevrolet Volt and Nissan Leaf began limited sales in select US cities in 2010 (EV Project 2011). Several other PEVs from a broad array of manufacturers are scheduled to enter the market soon. These include different types of vehicles such as the 2012 Ford Escape PHEV, which is a sports utility vehicle (SUV) (Plug In America 2011), and the Dodge Ram, which is a pickup truck (Automotive News 2011). Apart from vehicle type and seating capacity, two critical attributes are battery capacity and range. While the total range of a PHEV is much more than its AER, the AER determines the owner's likely operating cost savings, petroleum avoidance, and emissions impact. According to Tuttle and Kockelman (2012), expected BEVs tend to have AERs between 60 and 300 miles, while expected PHEVs have AERs between 10 and 80 miles.

The 2011 Chevrolet Volt PHEV is a four-door sedan with a manufacturer suggested retail price (MSRP) of $\$ 32,780$ after a $\$ 7,500$ of tax rebate provided by the U.S. government (Chevrolet 
2011). It has a battery size of $16 \mathrm{kWh}$, and the U.S. EPA has rated it to have an AER of 35 miles under average driving conditions (EPA 2011). A close ICE counterpart of the Chevrolet Volt is the 2011 Chevrolet Cruze, which has an MSRP of $\$ 16,525$ (Chevrolet 2011). The Toyota Prius PHEV, scheduled for release in 2012, is speculated to have an MSRP of $\$ 33,500$ after a federal $\$ 2,500$ tax rebate (USA TODAY 2010). Its battery pack is smaller than the Chevrolet Volt, at only $5.2 \mathrm{kWh}$ and will provide an AER of only 13 miles (Plug In America 2011). The Ford Escape PHEV is expected to be released into the market in 2012; it is an SUV with an anticipated AER of 40 miles (Plug In America 2011).

Several manufacturers are (or will be) offering BEVs for customers. The 2009 Tesla Roadster is a two-door sports car with a 53kWh battery and an AER of 245 miles (Tesla 2011). After an eligible $\$ 7,500$ tax rebate, its $\$ 101,500$ price remains substantial. A more affordable $\mathrm{BEV}$ is the 2011 Nissan Leaf, a four-door hatchback with a battery size of $24 \mathrm{kWh}$ and an EPA-rated AER of 73 miles (Nissan 2011, EPA 2011). The Nissan Leaf has an MSRP of $\$ 25,280$ after an eligible $\$ 7,500$ tax rebate (Nissan 2011). A close ICE equivalent to the Nissan Leaf is the 2011 Nissan Versa 1.8L hatchback, which has an MSRP of $\$ 17,410$ (Nissan 2011). Other popular manufacturers, such as BMW, Mercedes, Honda and Toyota, have released or are releasing their own BEVs (Plug In America 2011).

\section{DATA DESCRIPTION}

The data were obtained from the Puget Sound Regional Council's (PSRC) 2007 Traffic Choices Study across 264 households (and their 445 vehicles) residing in King, Kitsap, Pierce and Snohomish counties of Washington State. The data was collected between November 2004 and April 2006 using in-vehicle GPS devices and was provided through the National Renewable Energy Laboratory's (NREL) Secure Transportation Data Project. Due to the sensitive nature of the GPS data and privacy constraints, access to household demographics and vehicle locations was not feasible. Nevertheless, this rich data set includes lengths and trip durations for each vehicle at all times of each day over an extended period of time. In addition, household characteristics such as income and vehicle ownership levels are reported, as shown in Table 1. Figure1 illustrates one vehicle's daily-VMT information over 365 days, as extracted from the data set. 


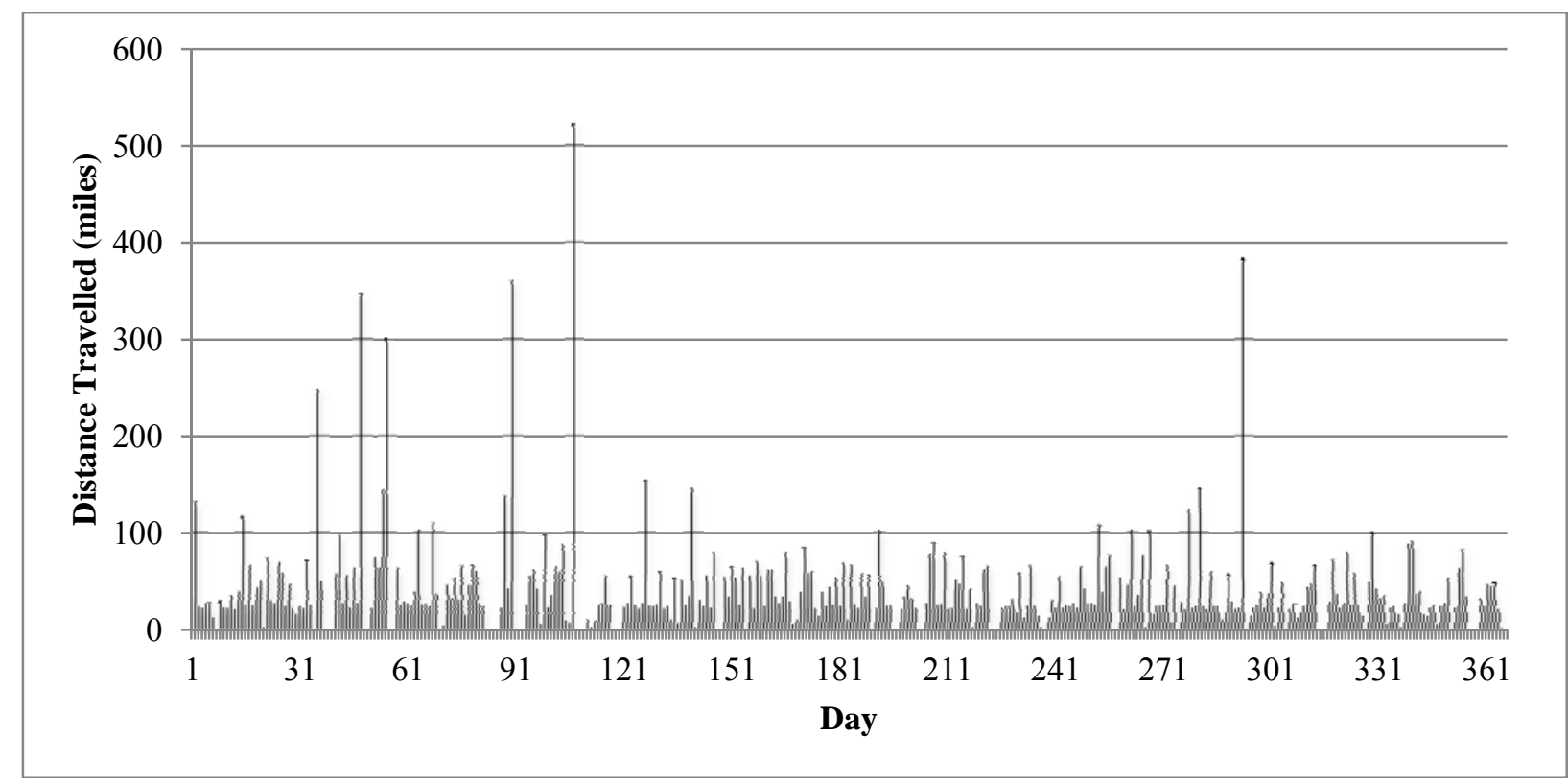

Figure 1 GPS Data Representation of Daily VMT for a Single Sampled Vehicle

Travel patterns of individuals vary substantially over time, which is why multi-day data, as opposed to conventional single-day data, can provide better insights into travel behavior (Pendyala and Pas 2000). Although the number of households surveyed in these data is relatively small, Stopher et al. (2008) showed how the required sample size to attain meaningful results can be significantly reduced in the case of multiday surveys. Hence, these data may characterize the travel behavior of metropolitan Seattle households rather well, once corrected for sample biases. To better represent the study area population, each sampled household was weighted using the American Community Survey (ACS) microdata sample for the PSRC's four counties using the population shares matched on number of vehicles, home-ownership status, and annual household income.

Descriptive statistics of the unweighted data along with some statistics from Seattle's American Community Survey are shown in Table 1. The average number of drivers and vehicles are 1.63 per household in the PSRC data, compared to 2.04 in the ACS data. The average household income is clearly lower at $\$ 46,658$ per year compared to $\$ 81,533$ per year in the ACS data. The average age of the sampled drivers is about 45 years, which is somewhat older than the region's 39 ; and a majority of these $(60 \%)$ are females, compared to $51 \%$ for the region. Most of the respondents are fully or partially employed $(81 \%)$ and the rest of them are home-makers $(10 \%)$, students $(6 \%)$ or unemployed $(3 \%)$.

The data set contains 269,357 trip records where the average trip is about 16 miles. These trip records correspond to 143,004 vehicle-days of data where each vehicle-day implies a day's worth of data for one vehicle. While the average Seattle trip length of 15.5 miles, as captured by the GPS device and coded into the data set by the data managers, appears as significantly longer than the U.S. average of 10.1 (from the 2009 National Household Travel Survey [NHTS]), the daily VMT is somewhat lower, at 25.4 miles, versus 29.0. Of course, these are unweighted statistics, to show the biases in the sample. Weighting, which is used on all values presented 
from here forward (including estimated shares of households able to switch to a PEV), offsets these to a significant degree.

Table 1 Data Set Description (Unweighted)

\begin{tabular}{|c|c|c|c|c|c|}
\hline Variable & Mean & $\begin{array}{c}\text { Std. } \\
\text { Deviation }\end{array}$ & Maximum & Minimum & $\begin{array}{c}\text { Seattle } \\
\text { ACS } \\
\text { Average }\end{array}$ \\
\hline \multicolumn{6}{|l|}{ Household records $(N=255)$} \\
\hline Number of drivers & 1.64 & 0.66 & 5 & 1 & \\
\hline Number of vehicles & 1.64 & 0.67 & 5 & 1 & 2.04 \\
\hline Own home indicator & 0.82 & 0.38 & 1 & 0 & 0.73 \\
\hline Rented home indicator & 0.18 & 0.38 & 1 & 0 & 0.27 \\
\hline Number of kids & 0.65 & 1.00 & 7 & 0 & \\
\hline Household income (\$/year) & 67,528 & 46,823 & 300,000 & 0 & 81,533 \\
\hline \multicolumn{6}{|l|}{ Driver records $(N=419)$} \\
\hline Age (years) & 44.6 & 12.5 & 81 & 15 & 38.6 \\
\hline Female Indicator & 0.60 & 0.49 & 1 & 0 & 0.51 \\
\hline Education (years) & 10.3 & 7.98 & 26 & 0 & 11.0 \\
\hline Full-time employment status & 0.67 & 0.47 & 1 & 0 & 0.59 \\
\hline & & & & & $\begin{array}{c}\text { U.S. } \\
\text { NHTS }\end{array}$ \\
\hline \multicolumn{5}{|l|}{ Trip records $(N=269,357)$} & Average \\
\hline VMT per trip (miles) & 15.5 & 27.6 & 776.1 & 0.2 & 10.1 \\
\hline Drive time per trip (minutes) & 34 & 40 & 897 & 3 & 19 \\
\hline \multicolumn{6}{|l|}{ Vehicle-day records $(N=143,004)$} \\
\hline Number of days per vehicle & 341 & 54 & 366 & 34 & \\
\hline VMT per day (miles) & 25.4 & 12.3 & 89.1 & 2.0 & 29.0 \\
\hline
\end{tabular}

Some of the cases were not usable due to missing values, inconsistency in reporting, very short series of daily-use records and/or nonsensical values. These observations were dropped. In addition, zero-VMT days had to be synthesized since the data set did not report any travel when the instrumented car was not driven. It was assumed that whenever a vehicle did not report any travel on a given day, it did not travel that day. The final data set consisted of 255 households, 424 vehicles and 419 drivers over 143,004 vehicle-days; thus, there was an average of 341 days of useful data per vehicle.

\section{DATA ANALYSIS}

The population-corrected data were analyzed to determine which households might reasonably replace an existing vehicle with a PEV. Households were divided into single-vehicle households and multiple-vehicle households and then divided further, into six cases total, as shown in Figure 
2. Cases 1 and 2 are for single-vehicle households replacing their car with a BEV or a PHEV, respectively.

The multiple-vehicle household scenario is more complex. Cases 3 and 4 are for multiple-vehicle households swapping one of their vehicles with a BEV, and cases 5 and 6 are for PHEVs. In case 3 the household replaces the vehicle that travels fewer miles on average with a BEV and then uses a BEV for all travel made by that vehicle. In case 4, the household replaces any of its existing vehicles, and then uses a BEV to meet travel needs of the driver that travels fewer miles each day, on a day-to-day basis. Of course, all BEV owners will not always know in advance how far they will need to drive their vehicles each day. So these two assignment-to-driver cases (3 and 4) present the extreme assignment examples, and actual shares (of days covered by a BEV's range) presumably will lie somewhere between their two percentages.

PHEVs do not have any special range limitations (relative to ICEs) and can quickly refuel at gas stations on long trips. To maximize a household's use of electric power, PHEVs may be assigned to a household's longer daily drives. Cases 5 and 6 involve the use of the PHEV by the higherVMT vehicle in the household - as estimated on average (Case 5) or on a day-to-day basis (Case 6). These two cases also are meant to capture the two extremes of vehicle assignment, and actual shares (of electrified miles) will lie somewhere in between. (Of course, PEV owners can also recharge more than once a day, increasing the percentages further.)

Two key questions are tackled under these six cases, as shown in Figure 2. For BEV owners, the percentage of days that can be covered by the household's BEV is anticipated (Cases 1, 3 and 4). For PHEV owners, the percentage of household miles that are electrified under different scenarios is predicted (Cases 2, 5 and 6).

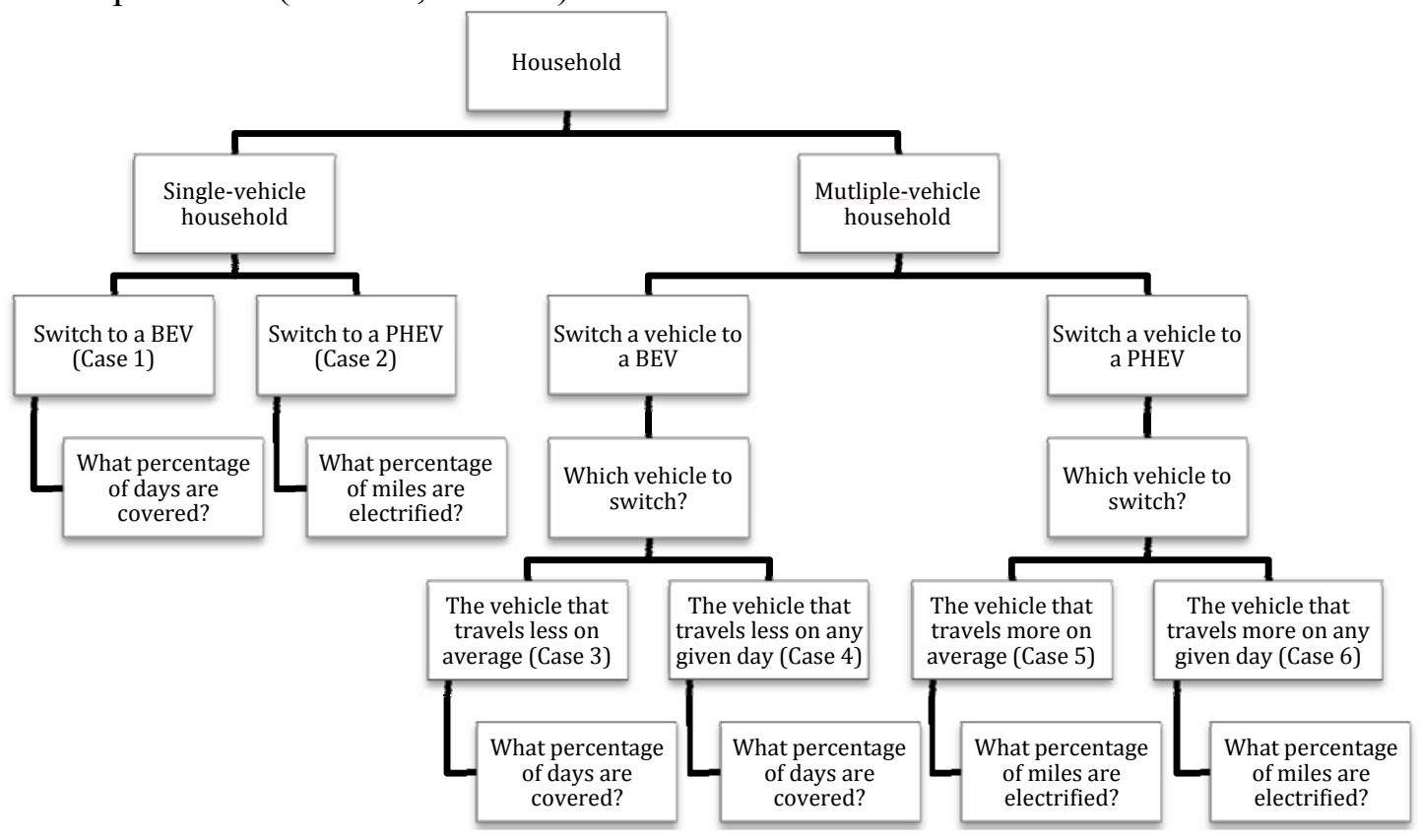

Figure 2 PEV Assignment to Seattle Households 


\section{Percentage of Days Covered Using a BEV}

If the AER of a BEV is more than the total miles driven by a Seattle vehicle on a given day, that day is "covered" by the BEV. For each replaced vehicle, the number of days that can be covered using a BEV is divided by the number of days in the household's data series to find the share of days whose travel needs can be met by the adjusted fleet. It is assumed that a household is likely to switch to a BEV if a high percentage of days can be covered when owning a BEV. Since the minimum target on travel-met days is not known and likely to vary from household to household, two extreme values $(90 \%$ and $99 \%)$ and a midpoint value $(95 \%)$ were used here, assuming that this range should capture the preferences and needs of the great majority of vehicle-owning households. For the small share of longer trips that cannot be covered by a BEV, some households would be able to charge their cars mid-trip, use rental cars or swap vehicles or modes for a day or more. The percentage of days that can be covered using a BEV was calculated for each household.

The (population-corrected) shares of Seattle households that can replace a vehicle under each of these three percentage values $(90,95$ and $99 \%)$ were calculated. The method was repeated for BEVs of different AERs, and plots of household percentages (three different plots corresponding to 90,95 and 99\%). Figures 3, 5 and 6 depict the three cases (1, 3 and 4) of BEV adoption.

\section{Percentage of Miles Electrified using a PHEV}

If a PHEV's AER exceeds the miles travelled on a given day, all miles were assumed to be electrified. If not, just the AER portion of miles was assumed electrified. The number of miles electrified each day for each vehicle was used to determine the percentage of miles electrified for each replacement PHEV (over the period of each household's data). The mean of these percentages is used as an indication of the share of miles that can be electrified at that AER. The method was repeated for different PHEV AERs, and a plot of electrified miles against AERs was created. For multiple-vehicle households, the percentage of total household miles electrified was plotted (instead of the percentage of the PHEV's miles). Figures 4 and 7 show the plots corresponding to PHEV adoption as outlined in cases 2, 5 and 6. The results of these calculations are discussed below.

\section{RESULTS}

The two cases involving single-vehicle households are discussed first below followed by the four cases involving multiple-vehicle households.

\section{Case 1: Single-vehicle Households Switching to a BEV}

For the single-vehicle households two plots are provided. Figure 3 shows how the percentage of Seattle's single-vehicle households that can replace their existing vehicle with a BEV varies across AER levels. The analysis was done for AERs of 60, 70, 80, 90, 100 and 120 miles and quadratic least-squares regression lines are shown. 


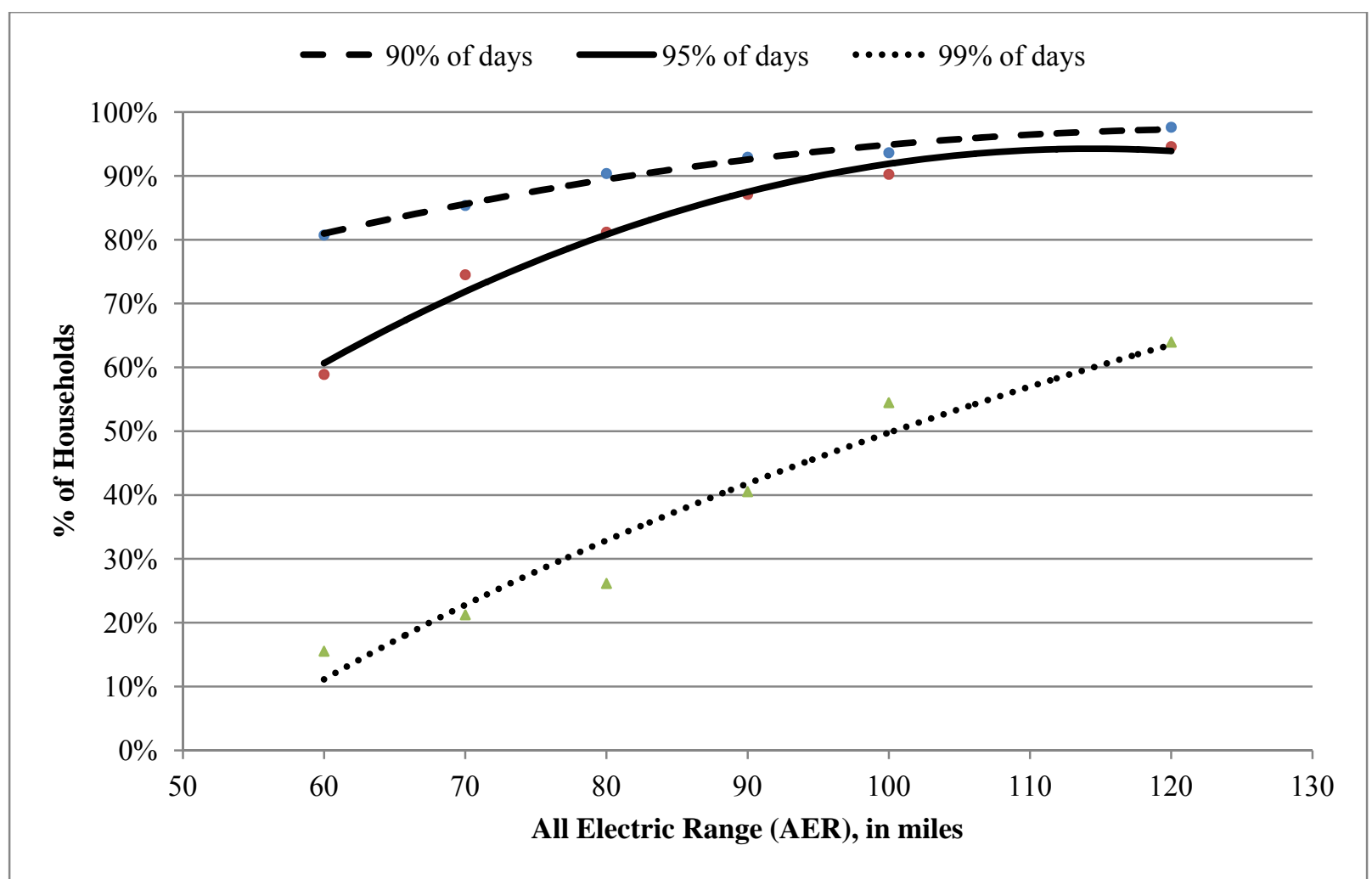

Figure 3 Maximum Possible Single-vehicle Household Adoption Rates for BEVs in Seattle (Case 1)

The dashed line suggests how household adoption rates may vary if households switched to BEVs assuming just $90 \%$ or more days in a year must be met by the BEV's AER. The results suggest that BEVs with AERs as low as 60 miles would meet $80 \%$ of Seattle's one-vehicle households' travel needs. This is a very relaxed case and will be unrealistic for households who do not want to rely on other forms of transportation $10 \%$ of the time, or 37 days a year.

Ideally, households would be willing to switch if all of their travel needs can be met by a BEV. The $99 \%$ case is more compelling since it implies that the household will need to find some other means of transportation just 4 days a year. The $99 \%$ case is shown in the dotted line. As can be seen from the plot, the percentage of single-vehicle households able to meet $99 \%$ of their days' travel needs drops significantly across AERs. At an AER of 90 miles, only $40 \%$ of the Seattle's single-vehicle households appear able to switch.

Finally, the solid line shows the $95 \%$ case, where households would have to rely on some other vehicle for transportation about 18 days a year. The $95 \%$ and $90 \%$ cases suggest that there is ample opportunity in the Seattle and U.S. markets for regular reliance on BEVs with $60+$ mile AERs - even in households with just one vehicle - far more than current adoption predictions. For example, microsimulations of Austin households by Musti and Kockelman (2009) suggest just a $19 \%$ fleet composition of PHEVs plus HEVs within 25-years. Similar microsimulations by Paul et al. (2011) for the U.S. market suggest a PHEV fleet share of 3.31\% over a 25 -year horizon when gas prices are held high (\$5.00/gallon) and PHEV prices are relatively low. In 
reality, no one knows what the future will hold, due to uncertainty in innovations, fuel prices, government regulation, and consumer motivation.

\section{Case 2: Single-vehicle Households Switching to a PHEV}

Figure 4 shows how share of electrified miles may vary with AER for single-vehicle households if they replace their existing vehicle with a PHEV. The single-vehicle households are divided into three categories based on their daily VMT, with cut points of 15 and 30 miles per day. The weighted-average single-vehicle household's daily VMT in the Seattle region is 23.4 miles per day.

The analysis was performed for AERs of 10, 20, 40 and 60 miles and a logarithmic fit was applied for the trend line (since it provided the best fit). Vehicles that travel less on average are able to electrify more of their miles since they stay within or around the AER on more days.

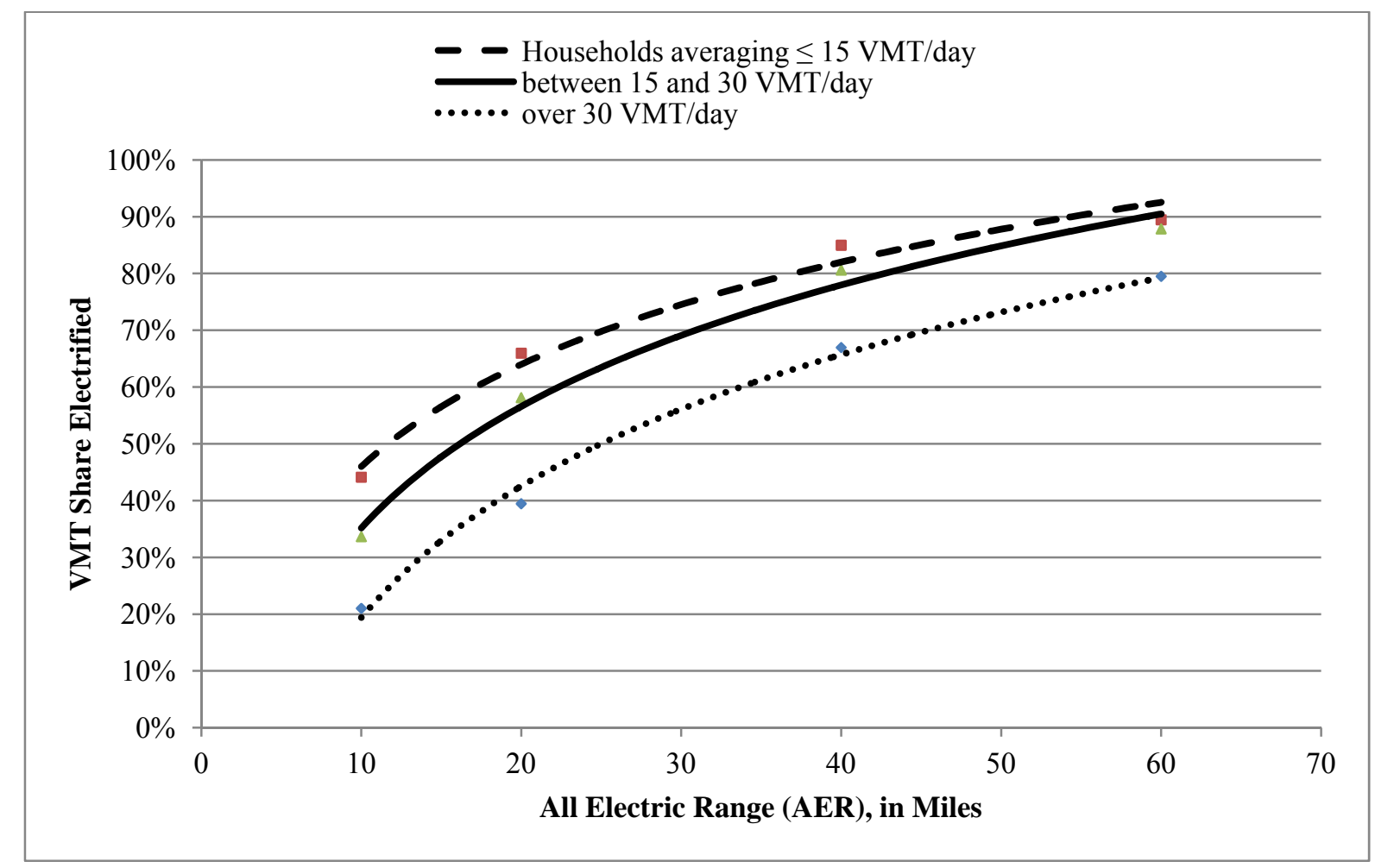

Figure 4 Share of VMT Electrified Using PHEVs in Single-vehicle Seattle Households (Case 2)

The results suggest that single-vehicle Seattle households that travel (on average) less than 15 miles per day can hope to electrify more than $90 \%$ of their miles with a PHEV60. A PHEV10, like the forthcoming Toyota Prius, which is less expensive, can electrify close to $50 \%$ of its miles if charged just once a day. The Chevrolet Volt has an AER of 35 miles, and should allow for more than 70\% electrified miles in single-vehicle households that travel (on average) between 15 and 30 miles per day. Single-vehicle households that travel on average more than 30 miles per day would require a PHEV25 to electrify at least $50 \%$ of their miles. Since single-vehicle 
households in the Seattle region travel 23 miles per day, to achieve at least $70 \%$ electrification, a PHEV of AER around 32 miles would be needed. Since the 2009 NHTS suggests that the average U.S. vehicle travels 29 miles/day (Table 1), the average single-vehicle U.S. household presumably will require a somewhat higher AER to achieve $70 \%$ electrification.

\section{Cases 3 and 4: Multiple-vehicle Household Adopting a BEV}

Similar analyses to determine the maximum possible BEV adoption rates were performed for multiple-vehicle households. Figures 5 and 6 show the percentage of multiple-vehicle households that can replace one of their existing vehicles with a BEV. The analysis was done for AERs of 40, 50, 60, 70, 80, 90, 100 and 120 miles and a quadratic function was used for the least-squares line.

Figure 5 presents the results of Case 3, where the household vehicle that travels less on average is replaced with a BEV. Figure 6 presents the results of Case 4 where the BEV replaces the vehicle that travels less on a day-to-day basis.

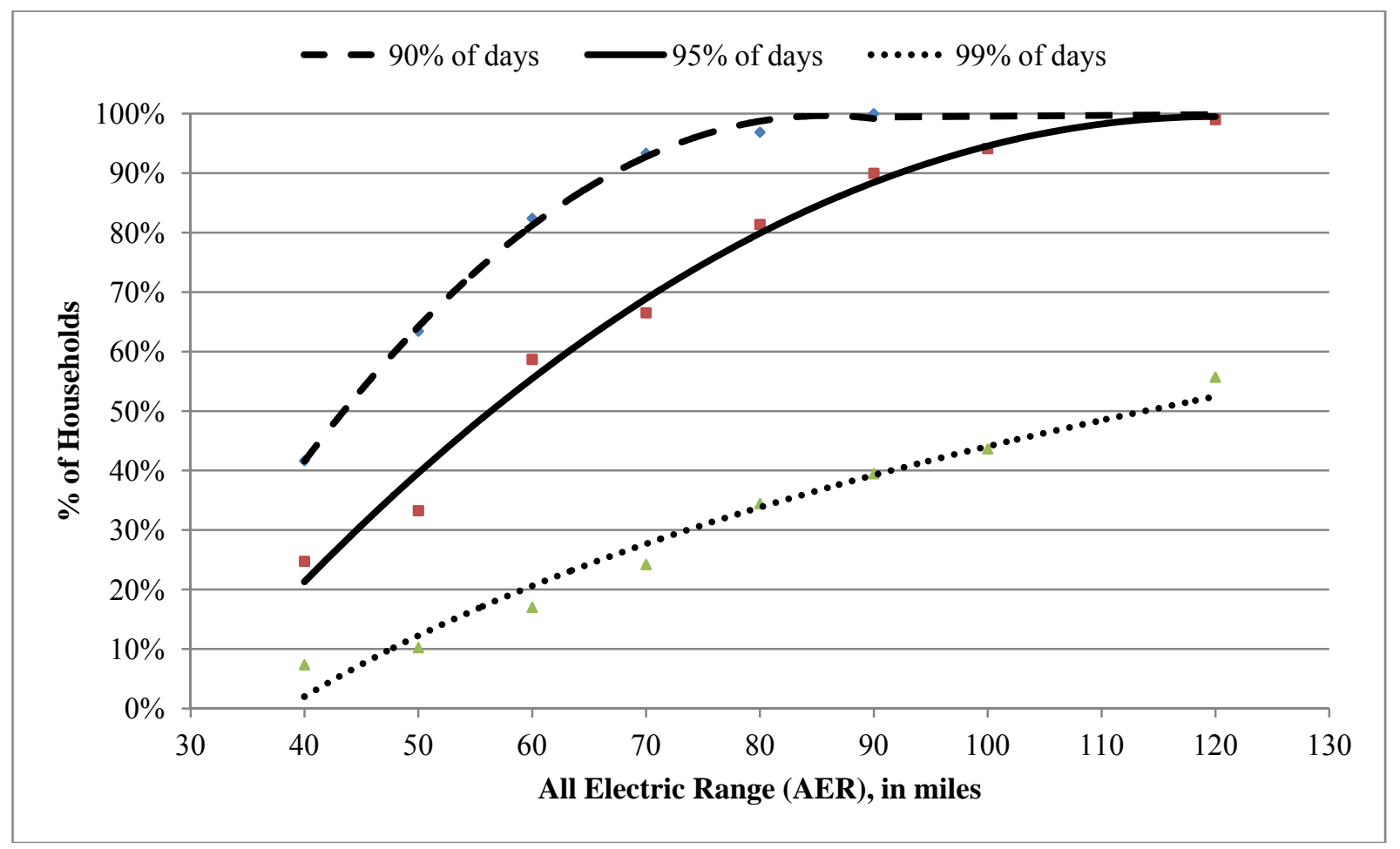

Figure 5 Maximum Possible Multiple-vehicle Household BEV Adoption Rates in Seattle, with BEV Replacing the Lower Overall-VMT Vehicle (Case 3) 


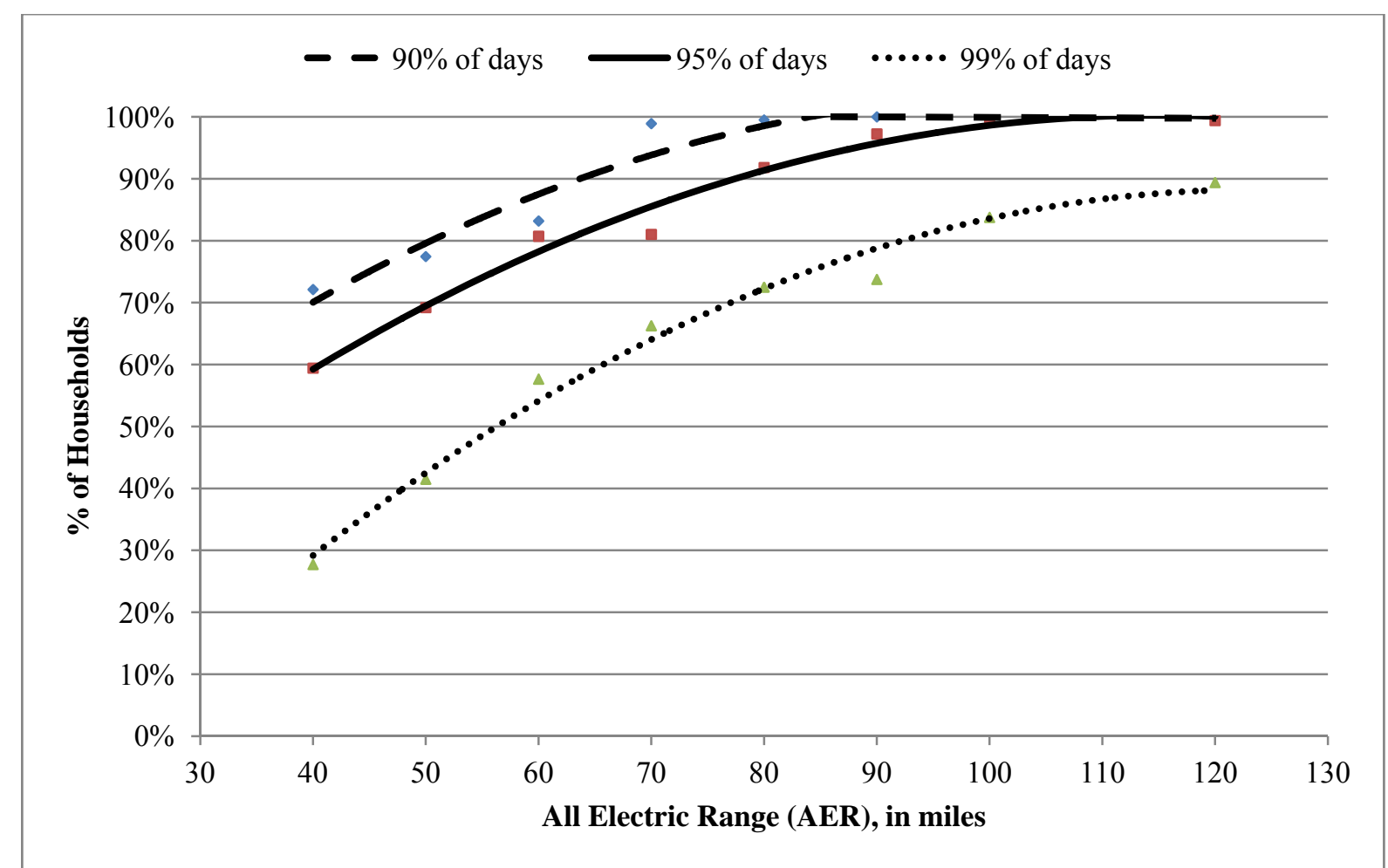

Figure 6 Maximum Possible Multiple-vehicle Household BEV Adoption Rates in Seattle, with BEV Replacing the Lower-VMT Vehicle on a Day-to-day Basis (Case 4)

A comparison of Figures 5 and 6 suggests that replacing the lower VMT vehicle on a day-to-day basis with a BEV (as shown in Figure 6) allows multiple-vehicle households to serve far more days' travel needs - with $99 \%$ of travel days' itineraries being met in $65 \%$ of such households with 70 mile AER versus just $28 \%$ of household contexts if the lower overall-VMT vehicle is used this way. As expected, these percentages are both higher than in Case 1, for a single-vehicle household with a BEV (which averaged 28\%) since multiple-vehicle households have more flexibility. In reality, many households tend to designate household members and only occasionally swap these among each other. Hence, one might safely assume that the actual percentage of households that can switch to a BEV lies somewhere in between Figures 5 and 6 extreme cases. For example, it can be understood that the actual percentage of multiple-vehicle households that can switch to a BEV of AER 70 miles lies between $65 \%$ and $80 \%$.

\section{Cases 5 and 6: Multiple-vehicle Households Adopting a PHEV}

Figure 7 shows travel miles in multiple-vehicle households that may be electrified using a PHEV (assuming once-a-day charging and two different vehicle-assignment rules [Cases 5 and 6]). The analysis was done for AERs of 10, 20, 30, 40, 50 and 60 miles and a quadratic fit forms the line. 


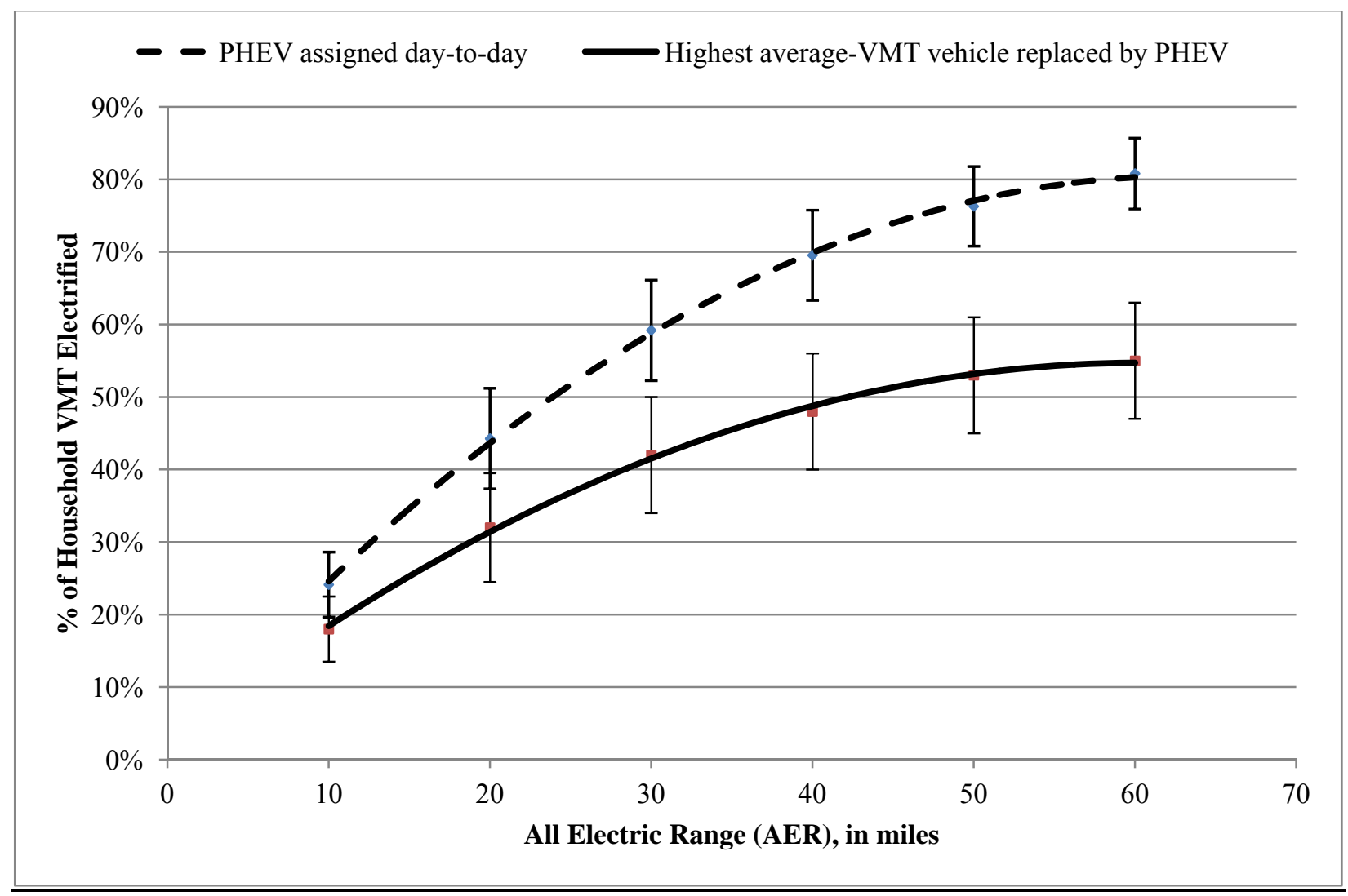

Figure 7 Average Shares of Household Miles Electrified (with Standard Deviations) using PHEVs in Multiple-vehicle Seattle Households

The solid line presents the results of Case 5, where the household vehicle that travels more on average is replaced by the PHEV. The dashed line presents the results of Case 6, where a PHEV replaces the vehicle that travels more on a day-to-day basis. As expected, Case 6 offers more electrified miles. As noted earlier, the actual share of household miles that are electrified will probably lie between these two cases. For example, such households can electrify about $50 \%$ of their household miles under Case 5 and 70\% under Case 6. The actual percentage of total household miles for multiple-vehicle households that can be electrified using a PHEV of AER 40 miles would lie between $50 \%$ and $70 \%$.

\section{COST COMPARISONS}

In this section, the monetary costs and benefits of switching to a BEV or a PHEV are estimated, as in Tuttle and Kockelman (2012). The 2010 Chevrolet Volt PHEV is compared to the 2011 Chevrolet Cruze, the 2010 Nissan Leaf BEV is compared to the 2011 Nissan Versa hatchback, and the upcoming 2012 Toyota Prius PHEV is compared to the 2011 Toyota Corolla. Since gas prices and electricity rates fluctuate over time and space, five gas-price scenarios $(\$ 2.50, \$ 3.50$, $\$ 4.50, \$ 5.50$ and $\$ 6.50$ per gallon) and three electricity-rate scenarios were considered in the analysis. The average electric rate across the U.S. is $11.2 \mathrm{ct} / \mathrm{kWh}$ (EIA 2011), so this rate was used as a base case along with $6.0 \mathrm{ct} / \mathrm{kWh}$ and $16.0 \mathrm{ct} / \mathrm{kWh}$. The current cost of electricity in Washington State is $8.0 \mathrm{ct} / \mathrm{kWh}$ (EIA 2011). Since the percentage of household miles that are 
electrified is similar for single- and multiple-vehicle households, analyses were performed just for single-vehicle Seattle households that replace their existing vehicle with a BEV or a PHEV. The vehicles were grouped into three categories based on their average daily VMT, with cutoff points at 15 and 30 miles. The calculations neglect any added costs of 220-voltage upgrade (for garage charging outlets) and other long-term cost differences (such as brake and oil-change savings from a PEV, and possible battery replacement costs); such differences are examined in Tuttle and Kockelman's (2012) cost analysis.

\section{Chevrolet Volt vs Chevrolet Cruze}

To calculate the annual energy cost savings of using the Volt, the share of VMT that is electrified at 35 miles AER for single-vehicle households was determined from Figure 4. The weightedaverage annual household mileage of Seattle's single-vehicle households was used to determine the energy cost differential. Electricity consumption and fuel-economy of the Volt were assumed to be $36 \mathrm{kWh}$ per 100 miles and 37 miles per gallon, respectively (EPA 2011). The MSRP of a similar Chevrolet Cruze (LTZ) is \$22,225 and its fuel economy 28 miles per gallon (Chevrolet 2011). The net price difference between the two vehicles is $\$ 10,555$ (since the Volt costs $\$ 32,780$ after a $\$ 7,500$ U.S. federal rebate). Table 2 provides the results of the cost comparison.

Table 2 Energy Cost Savings: Chevrolet Volt vs Chevrolet Cruze

\begin{tabular}{|c|c|c|c|c|c|}
\hline \multirow{4}{*}{$\begin{array}{l}\text { Electricity } \\
\text { price } \\
\text { (ct/kWh) }\end{array}$} & \multicolumn{5}{|c|}{ Annual Savings } \\
\hline & \multicolumn{5}{|c|}{ Gas Price } \\
\hline & $\$ 2.50 /$ gallon & \$3.50/gallon & $\$ 4.50 /$ gallon & $\$ 5.50 /$ gallon & \$6.50/gallon \\
\hline & \multicolumn{5}{|c|}{ Vehicle is driven on average $\leq 15$ miles/day, and 4,315 miles/year } \\
\hline 6.0 & $\$ 252$ & $\$ 383.2$ & $\$ 514.0$ & $\$ 645$ & $\$ 776$ \\
\hline 11.2 & $\$ 188$ & $\$ 318.6$ & $\$ 449.3$ & $\$ 580$ & $\$ 711$ \\
\hline \multirow[t]{2}{*}{16.0} & $\$ 128$ & $\$ 258.9$ & $\$ 389.7$ & $\$ 520$ & $\$ 651$ \\
\hline & \multicolumn{5}{|c|}{ Vehicle is driven on average between 15 and 30 miles/day, and 8,056 miles/year } \\
\hline 6.0 & $\$ 453$ & $\$ 686$ & $\$ 919$ & $\$ 1,153$ & $\$ 1,386$ \\
\hline 11.2 & $\$ 340$ & $\$ 573$ & $\$ 806$ & $\$ 1,039$ & $\$ 1,273$ \\
\hline \multirow[t]{2}{*}{16.0} & $\$ 235$ & $\$ 468$ & $\$ 702$ & $\$ 935$ & $\$ 1,168$ \\
\hline & \multicolumn{5}{|c|}{ Vehicle is driven on average more than 30 miles/day, and 14,886 miles/year } \\
\hline 6.0 & $\$ 734$ & $\$ 1,105$ & $\$ 1,475$ & $\$ 1,846$ & $\$ 2,217$ \\
\hline 11.2 & $\$ 567$ & $\$ 937$ & $\$ 1,308$ & $\$ 1,679$ & $\$ 2,050$ \\
\hline 16.0 & $\$ 412$ & $\$ 783$ & $\$ 1,154$ & $\$ 1,524$ & $\$ 1,895$ \\
\hline
\end{tabular}

The results show how vehicles that are driven less (e.g., 4,300 miles/year, or less than 15 miles/day), if replaced with a Volt instead of a Cruze offer hundreds of dollars of annual operating cost savings. However, given current MSRP differences, it would take such owners a long time to recover the added purchase cost of a Volt, even with the U.S. rebates. While vehicles that travel more have a smaller share of electrified miles, they will recover purchase costs faster, since their total of electrified miles is higher. The results show that vehicles that travel more than 30 miles/day on average, if replaced with a Volt instead of a Cruze, will close 
the initial cost gap in about 11 years (at a gas price of $\$ 3.50 /$ gallon and $11.2 \mathrm{ct} / \mathrm{kWh}$ electricity rate).

\section{Toyota Prius PHEV vs Toyota Corolla ICE}

Similar assumptions were used to determine the energy cost savings of a Prius over a Corolla. The Prius PHEV has not yet been rated by the EPA, so information provided by Toyota (2011) was used here. The Prius is said to enjoy a lower electricity consumption rate, of only $29 \mathrm{kWh}$ per 100 miles (Halvorson 2011). The Prius PHEV was assumed to achieve the same fuel economy as the 2011 Prius Hybrid: 50 miles/gallon (EPA 2011). The cost of the 2011 Toyota Corolla (1.8L, automatic transmission) is $\$ 18,600$ (compared to the Prius PHEV's estimated $\$ 33,500$, after rebate) (Toyota 2011) with a fuel economy of 29 miles per gallon (EPA 2011). The net price difference between the two vehicles is $\$ 14,900$.

Despite its low AER, the Prius PHEV's annual cost savings are almost as large as those shown in Table 2. When gas and electricity prices are $\$ 3.50 /$ gallon and $11.2 \mathrm{ct} / \mathrm{kWh}$, respectively, the Prius PHEV is expected to the average owner traveling more than 30 miles (on average) per day $\$ 911$ each year, as compared to the Toyota Corolla. Under this scenario, the Prius PHEV will close the initial cost gap within approximately 16 years. If gas prices are $\$ 4.50 /$ gallon, the annual savings increase to more than $\$ 1,200$ per year and the payback period falls under 13 years.

\section{Nissan Leaf vs Nissan Versa}

The 2010 Nissan Leaf BEV was compared to the 2011 Nissan Versa hatchback, which sells for $\$ 17,410$ (compared to the Leaf's $\$ 25,280$ after rebate). Since the Leaf is a BEV, the costs of renting a similar ICE vehicle and running it on gas on long-travel days that cannot be served by the BEV included. A \$50/day of car rental cost was assumed. According to the EPA (2011), the Leaf has an electricity consumption rate of $34 \mathrm{kWh}$ per 100 miles and the Versa has an overall fuel economy of $28 \mathrm{mi} / \mathrm{gal}$.

Unlike the Volt or Prius PHEV, the Leaf will not offer cost savings for owners under most scenarios, if an alternate vehicle must be rented at $\$ 50 /$ day on travel days exceeding this BEVs 73 mile AER. If a rental car is not needed, the Leaf enjoys similar annual fuel-cost savings to the Volt and Prius PHEV, over their ICE counterparts, for the various scenarios examined. For example, when gas and electricity prices are $\$ 3.50 /$ gallon and $11.2 \mathrm{ct} / \mathrm{kWh}$, respectively, the Leaf is estimated to save its owner $\$ 780$ annually, as compared to the Versa, for the typical vehicle that averages more than 30 miles per day, producing a payback period of 10 years. If gas prices are held at $\$ 4.50$ /gallon, the savings rise to more than $\$ 1,100$ dollars per year (suggesting a payback period of 8 years). The Leaf has a lower purchase price than the Volt or the Prius, which allows it to recover purchase costs faster.

\section{SOME CAVEATS}

The results rely on several assumptions one of which is that all PHEVs operate purely in electric mode over all initial miles corresponding to their AER. In reality, PHEVs use small amounts of gas even when operating in electric mode (Vyas et al. 2009), so the actual share of VMT electrified may be lower. 
It is also assumed that all households will charge their vehicles fully once a day. In reality, households may charge more than once on some days, partially charge on some days, and not charge at all on other days. Such flexibility will allow some households to meet more needs, if diligent about charging, especially when expecting long-distance travel days. Others may forget to charge and end up more range limited.

Electricity costs vary from region to region and may eventually vary by time of day. The operating-cost analysis uses only three different electricity rates (with average U.S. rate as a base). The purchase price difference may also vary, since some locations (such as California) offer additional financial (and non-financial) incentives for buying a PEV. Electric rates for other potential PEV markets (such as Japan or Europe [Deloitte 2011]) have not been considered here, but do offer much higher gas prices, so PEVs are expected to fare better there (especially with so many alternative travel-mode options).

During the cost calculations, costs of battery replacement (for PEVs) and transmission changes (for ICEs) were ignored. Other general costs, such as oil changes, and brake and battery replacements, will also affect the cost comparisons (as described in Tuttle and Kockelman 2012). The vehicles being compared are also not exactly similar, with each vehicle providing different sets of amenities. Adding amenities that may be missing from one or the other (e.g., the Volt enjoys several high-tech features that few vehicles yet have) will also affect the comparisons.

For BEVs, it is assumed that any day, during which the VMT is greater than the AER, the owner would rent a vehicle, which added additional costs to adopting a BEV. In practice, owners may be able to plan and distribute trips, or borrow a vehicle from a friend, so that they do not have to rent a vehicle. Such dynamics make the Leaf significantly more competitive with the Versa.

Other factors, such as access to garage ports for charging at home or work and being able to charge for adequate time every day, remembering to plug the vehicle in at intended times also have practical implications. The AHS data reveal that just $38.7 \%$ of US households have access to a garage or car port (Vyas et al. 2009), so other charging options are needed (including smart cards for outlet operation in public-lot settings). Other limitations may arise if there is massive adoption of PEVs, since that can put a strain on the utility company/local power delivery system (see, e.g., DeFreitas [2010]).

\section{CONCLUSIONS}

The results developed here provide valuable insights into the role of AER on PEV adoption feasibility and operating cost differences. As long as owners are willing to rely on a different form of transportation a few days every year, BEVs appear feasible for significant shares of single-vehicle and multiple-vehicle households in the Seattle area and presumably across the U.S. In fact, a 100-mile AER BEV appears feasible for $50 \%$ of single-vehicle households and more than $80 \%$ of multiple-vehicle households who swap vehicles (according to VMT needs) or $40 \%$ of multiple-vehicle households who simply replace their lowest overall-VMT vehicle with a $\mathrm{BEV}$ provided they are willing to change behavior just 4 days a year. The percentage of miles that may be electrified by a switch to a PHEV is higher for households that travel less. Households that travel 15 to 30 miles a day are able to electrify close to $80 \%$ of their miles using 
a PHEV40.The net energy cost savings is estimated to be higher for PHEVs than BEVs if one must rent a car on days whose travel needs cannot be met by a BEV.

With decreasing manufacturing costs for batteries in the long run (DOE 2011), with proper investment in charging infrastructure, by providing different financial and non-financial incentives, and by educating the public about their long-term travel needs, national energysecurity issues and emissions benefits, the world may see a rapid influx of PEVs. The results of this research provide some reasons for optimism.

\section{ACKNOWLEDGEMENTS}

We would like to thank the National Science Foundation for financial sponsorship of this work through the University of Texas at Austin and Texas A\&M's Industry-University Research Center for PEVs. The authors also appreciate data and other support provided by NREL's Jeff Gonder and Mr. Dave Tuttle of UT Austin, along with administrative support by Annette Perrone and the suggestions of anonymous reviewers.

\section{REFERENCES}

Automotive News (2011) Plug-in Hybrid Ram Pickup Fleet Rolls out in Arizona. Available at http://www.autonews.com/apps/pbcs.dll/article?AID=/20110525/OEM06/110529924/1403.

Axsen, J., and K. Kurani (2008) The Early U.S. Market for PHEVs: Anticipating Consumer Awareness, Recharge Potential, Design Priorities and Energy Impacts. Institute of Transportation Studies, University of California, Davis, Research Report UCD-ITS-RR-08-22.

Center for Sustainable Energy (2011) Clean Vehicle Rebate Project. Available at https://energycenter.org/index.php/incentive-programs/clean-vehicle-rebate-project.

Chevrolet (2011) Cars. Available at http://www.chevrolet.com/\#volt.

DeFreitas, S. (2010) New Study Forecasts Impact of Electric Vehicles on Power Grid. Earth Teaching. Available at http://www.earthtechling.com/2010/03/new-study-forecasts-impact-of-electric-vehicles-onpower-grid/.

Deloitte (2011) Fuel Prices will Influence Electric Vehicle Purchases says Deloitte. Available at http://www.deloitte.com/view/en_AU/au/news-research/mediareleases/7a0d2f4ce1a41310VgnVCM2000001b56f00aRCRD.htm.

DOE (2011) One Million Electric Vehicles by 2015. United States Department of Energy. Available at http://www.energy.gov/media/1_Million_Electric_Vehicle_Report_Final.pdf.

Duvall, M. and E. Knipping (2007) Environmental Assessment of Plug-In Hybrid Electric Vehicles, Volume 1: National Wide Greenhouse Gas Emissions, EPRI Technical Report. 
EIA (2011) Average Retail Price of Electricity to Ultimate Customers by End-Use Sector, by State. Available at http://www.eia.gov/cneaf/electricity/epm/table5_6_a.html.

EPA (2011) Find and Compare Cars. U.S. Environmental Protection Agency. Available at http://www.fueleconomy.gov/feg/findacar.htm.

EV Project (2011) The Largest Deployment of EVs and Charge Infrastructure. Available at http://www.theevproject.com/overview.php.

Fontaine, P.J. (2008) Shortening the Path to Energy Independence: A Policy Agenda to Commercialize Battery-Electric Vehicles. The Electricity Journal, 21: 22-42.

Frost \& Sullivan (2009a) Strategic Analysis of North American Passenger Electric Vehicle Market. Available at http://www.frost.com/prod/servlet/report-toc.pag?repid=N598-01-00-00-00.

GM-Volt (2011) Official 2011 Chevrolet Volt EPA Fuel Economy Released. Available at http://gmvolt.com/2010/11/24/official-2011-chevrolet-volt-epa-fuel-economy-released/.

Gonder, J., Markel, T., Thornton, M. and Simpson, A. (2007) Using global positioning system travel data to assess real-world energy use of plug-in hybrid electric vehicles. Transportation Research Record 2017: 26-32.

Gordon-Bloomfield, N. (2011) Tesla Triumphs with Ten Million Miles Travelled Since Launch. Available at http://www.allcarselectric.com/news/1057495_tesla-triumphs-with-ten-million-milestravelled-since-launch.

Greene, D.L. (2010a) Measuring Energy Security: Can the United States Achieve Oil Independence? Energy Policy 38 (4): 1614-1621.

Halvorson, B. (2011) By the Numbers: the 2012 Plug-in Prius. Reuters. Available at http://www.reuters.com/article/2011/03/24/idUS164234781620110324.

Kintner-Meyer M., K. Schneider, and R. Pratt (2007) Impact Assessment of Plug-in Hybrid Vehicles on Electric Utilities and Regional US Power Grids. Part I: Technical Analysis. Pacific Northwest National Laboratory paper. Available at http://www.pnl.gov/energy/eed/etd/pdfs/phev_feasibility_analysis_combined.pdf.

Lemoine, D., Kammen D. and Farrell, E. (2008) An Innovation and Policy Agenda for Commercially Competitive Plug-in Hybrid Electric Vehicles. Environmental Research Letters Vol. 3 No. 1.

Musti, S., and K.M. Kockelman. (2011). Evolution of the Household Vehicle Fleet: Anticipating Fleet Composition and PHEV Adoption and GHG Emissions in Austin, Texas. Transportation Research Part A 45 (8):707-720.

Nissan (2011) See all Vehicles website. Nissan USA. Available at http://www.nissanusa.com/sav/. 
Paul, B., Kockelman, K. and Musti, S. (2011) Evolution of the Light-Duty Vehicle Fleet: Anticipating Adoption of Plug-In Hybrid Electric Vehicles and Greenhouse Gas Emissions Across the U.S. Fleet. Transportation Research Record No. 2252:107-117.

Available at http://www.ce.utexas.edu/prof/kockelman/public_html/TRB11FleetEvolutionUS.pdf.

Pearre, N., Kempton, W., Guensler, R. and Elango, V. (2011) Electric Vehicles: How Much Range is Required for a Day's Driving? Transportation Research Part $C$, article in press: doi:10.1016/j.trc.2010.12.010.

Pendyala, R. and Pas, E. (2000) Multi-Day and Multi-Period Data for Travel Demand Analysis and Modeling. In TRB Transportation Research Circular EC008: Transportation Surveys: Raising the Standard.

Plug In America (2011) Plug-in Vehicle Tracker: Whats Coming, When. Available at http://www.pluginamerica.org/vehicles.

Samaras, C. and Meisterling, K. (2008) Life Cycle Assessment of Greenhouse Gas Emissions from Plugin Hybrid Vehicles: Implications for Policy. Environmental Science and Technology 42: 3170-3176.

Simpson, A. (2006) Cost-Benefit Analysis of Plug-In Hybrid Electric Vehicle Technology. Presented at the 22nd International Battery, Hybrid and Fuel Cell Electric Vehicle. Symposium (EVS-22). Yokohama, Japan.

Sioshanshi, Ramteen, and Paul Denholm (2008) Emissions Impacts and Benefits of Plug-in Hybrid Electric Vehicles and Vehicle to Grid Services. National Renewable Energy Laboratory Conference Paper. Available at http://www.iwse.osu.edu/ISEFaculty/sioshansi/papers/PHEV_emissions.pdf.

Sperling, D. and N. Lutsey (2009) Energy Efficiency in Passenger Transportation. The Bridge, 39(2): 22-30.

Stopher, P., Kockelman, K., Greaves, S. and Clifford, E. (2008) Reducing Burden and Sample Sizes in Multiday Household Travel Surveys. Transportation Research Record 2064: 12-18.

Tate, E. D., M.O. Harpster, and P.J. Savagian (2008) The Electrification of the Automobile: From Conventional Hybrid, to Plug-in Hybrids, to Extended-Range Electric Vehicles. SAE International World Congress. SAE Technical Paper 2008-01-0458.

Taylor D. (2009) The Differences and Similarities between Plug-in Hybrid EVs and Battery EVs. Available at http://www.cars21.com/files/papers/Taylor-paper.pdf.

Tesla (2011) The New Roadster. Available at http://www.teslamotors.com/roadster. 
Thompson, Tammy, Michael Webber, and David Allen (2009) Air quality impacts of using overnight electricity generation to charge plug-in hybrid electric vehicles for daytime use. Environmental Research Letters 4 (1)

Toyota (2011) The First-ever Prius Plug-in Hybrid. Available at http://www.toyota.com/upcomingvehicles/prius-plug-in/technology.html.

Tuttle, D. and Kockelman, K. (2012) Electrified Vehicle Technology Trends, Infrastructure Implications and Cost Comparisons. Forthcoming in the Journal of the Transportation Research Forum. Proceedings of the $91^{\text {st }}$ Annual Meeting of the Transportation Research Board, Washington D.C.

Vyas, Anant, Dan Santini, and Larry Johnson (2009) Plug-In Hybrid Electric Vehicles' Potential for Petroleum Use Reduction: Issues Involved in Developing Reliable Estimates. Transportation Research Record 2139: 55-63.

\section{LIST OF TABLES \& FIGURES}

Table 1 Data Set Description (Unweighted)

Table 2 Energy Cost Savings: Chevrolet Volt vs Chevrolet Cruze

Figure 1 GPS Data Representation for a Single Smapled Vehicle

Figure 2 PEV Assignment to Seattle Households

Figure 3 Maximum Possible Single-vehicle Household Adoption Rates for BEVs in Seattle (Case 1)

Figure 4 Share of VMT Electrified Using PHEVs in Single-vehicle Seattle Households (Case 2)

Figure 5 Maximum Possible Multiple-vehicle Household BEV Adoption Rates in Seattle, with BEV Replacing the Lower Overall-VMT Vehicle (Case 3)

Figure 6 Maximum Possible Multiple-vehicle Household BEV Adoption Rates in Seattle, with BEV Replacing the Lower-VMT Vehicle on a Day-to-day Basis (Case 4)

Figure 7 Average Shares of Household Miles Electrified (with Standard Deviations) using PHEVs in Multiple-vehicle Seattle Households

\section{HIGHLIGHTS}

- Daily travel distances over a year were obtained for 255 Seattle households.

- 100-mi-range BEVs can meet $99 \%$ of daily needs for $50 \%$ of one-vehicle households.

- 100-mi-range BEVs can meet $99 \%$ of needs for $80 \%$ of multi-vehicle households.

- 1-vehicle households will electrify close to $80 \%$ of its miles using a PHEV40.

- $2+$ vehicle households can electrify 50 to $70 \%$ of household miles using a PHEV40. 